\title{
Disappearance of Crohn's ulcers in the terminal ileum after thalidomide therapy
}

\author{
NB Hershfield MD FRCPC FACP
}

\begin{abstract}
NB Hershfield. Disappearance of Crohn's ulcers in the terminal ileum after thalidomide therapy. Can J Gastroenterol 2004;18(2):101-104.
\end{abstract}

A case of intractable Crohn's disease unresponsive to all forms of therapy, including multiple operations and medication, is reported. The patient responded to thalidomide and this has resulted in the disappearance of the disease in the neoterminal ileum.

Thalidomide may be a valuable treatment in intractable cases of Crohn's disease.

The case is presented in a chronological fashion and endoscopic photographs documenting the disappearance of the disease are presented.

\section{La disparition d'ulcères de Crohn dans l'iléon terminal après un traitement à la thalidomide}

\begin{abstract}
Est exposé un cas de maladie de Crohn réfractaire ne répondant à aucune forme de traitement, y compris de multiples opérations et médicaments. Le patient a répondu à la thalidomide, et sa maladie a disparu dans l'iléon néoterminal.

La thalidomide pourrait constituer un traitement intéressant dans les cas de maladie de Crohn réfractaire.

Le cas est présenté de manière chronologique, accompagné de photographies endoscopiques documentant la disparition de la maladie.
\end{abstract}

Key Words: Crohn's disease, intractable; Thalidomide

$\mathrm{T}_{\mathrm{t}}^{\mathrm{b}}$ halidomide has been shown to have antitumour necrosis factor (anti-TNF) properties and has been reported to be effective in two open-label studies dealing with Crohn's disease $(1,2)$. The first report of this phenomenon appeared in the Lancet in 1997 in a paper by Wettstein and Meagher (3). They reported the case of a 32-year-old woman who had had multiple small bowel and colonic resections for complicated Crohn's disease resulting in short bowel syndrome. The patient was treated with all of the current medications at the time, including total parenteral nutrition, metronidazole and cyclosporine, without success. The patient was then treated with $300 \mathrm{mg}$ of thalidomide per day, and the report stated that aside from sleepiness, no other side effects were noted. The patient was maintained on $100 \mathrm{mg}$ of thalidomide daily up until the time of the report with resolution of the disease.

The following case report further expands the clinical experience with this drug, and other case reports regarding the efficacy of this drug in the disease are summarized.

\section{CASE PRESENTATION}

A 29-year-old man was first seen in 1994 with increasing abdominal pain, weight loss and vomiting. The previous history was significant in that in 1991 he presented at the Cranbrook Regional Hospital in British Columbia with a perforation of the terminal ileum, secondary to Crohn's disease, of which he was previously unaware. At that time he had a right hemicolectomy and recovered uneventfully.
When seen in 1994, investigation revealed a partial small bowel obstruction and hospitalization was necessary. He was treated with intravenous corticosteroids and nasogastric suction, but his bowel obstruction did not resolve. A resection of the neoterminal ileum was then performed. Surgical pathology revealed Crohn's disease of the neoterminal ileum and the right colon. His postoperative course was marred by intraabdominal bleeding. The patient had to be returned to the operating room where the anastomosis was found to be ruptured and he required a reconstruction and reanastomosis. No further problem was encountered and he was discharged.

In late 1994 he was seen because of persistent lower abdominal cramps and passage of bright red blood in his stools. He had lost much time from work and could not carry on because of weakness, diarrhea and fatigue. He had had multiple transfusions of blood. His hemoglobin remained between $80 \mathrm{~g} / \mathrm{L}$ and $100 \mathrm{~g} / \mathrm{L}$ throughout the six months that he was seen.

Repeat investigations revealed recurrent Crohn's disease of the terminal ileum, as demonstrated by a colonoscopy. Despite treatment with corticosteroids and azathioprine $100 \mathrm{mg} /$ day over the next year, the bleeding, anemia and weight loss persisted. Another surgical procedure was therefore carried out in 1996, where a further $10 \mathrm{~cm}$ of the terminal ileum was resected.

Crohn's disease was again demonstrated by histological studies of the resected segment. In 1997 he was seen once again for persistent bleeding and anemia. Colonoscopy once 


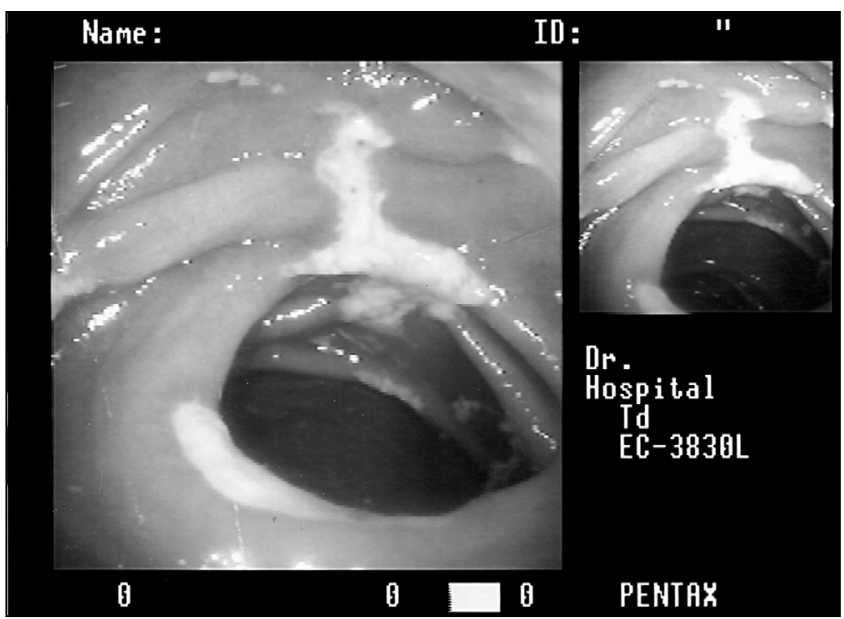

Figure 1) Colonoscopic demonstration of ileal ulcers, June 1998

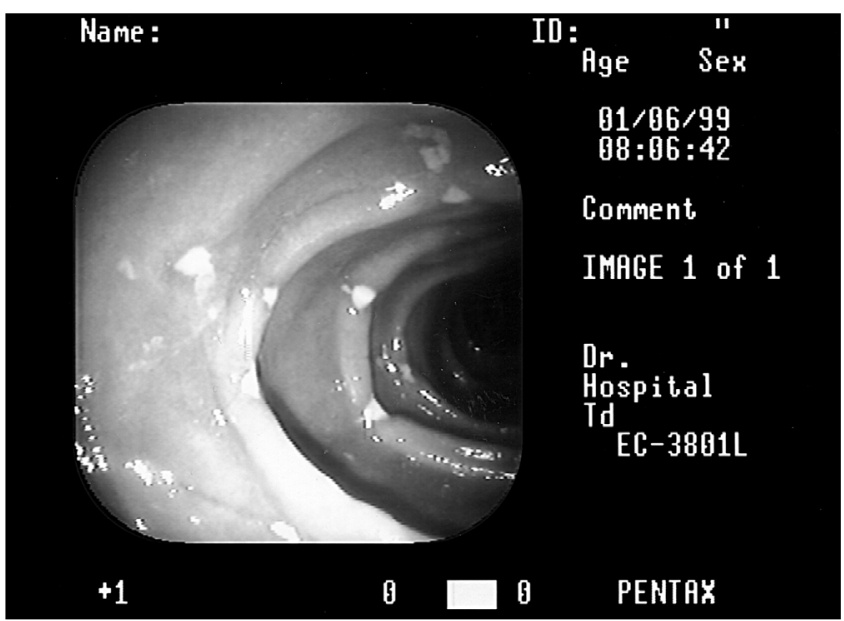

Figure 2) Colonoscopic demonstration of the reduction in size of ileal ulcers six months after initiation of thalidomide, January 1999

again demonstrated terminal ileal ulcers, which were consistent with Crohn's disease on biopsy (Figure 1). The colon was normal.

At this time he was started on methotrexate $25 \mathrm{mg}$ intramuscularly per week for 12 weeks; however, no improvement was noted. He was also being treated at this time with corticosteroids and azathioprine $100 \mathrm{mg} /$ day. His problem persisted and he was seen again in 1998 where repeat colonoscopy revealed terminal ileal ulcers and surgery was once again considered.

At this time the paper by Wettstein and Meagher (1) came to the author's attention, and after some discussion with the patient he was placed on thalidomide at $100 \mathrm{mg} /$ day. All other medication was discontinued. The patient returned to his home town and communication with his general practitioner revealed that the bleeding had ceased and his hemoglobin was finally beginning to rise. Six months later it reached a level of $156 \mathrm{~g} / \mathrm{L}$, the highest in many years. During this period of time the patient developed two side effects of the drug, which were headache and diplopia. These side effects both subsided when

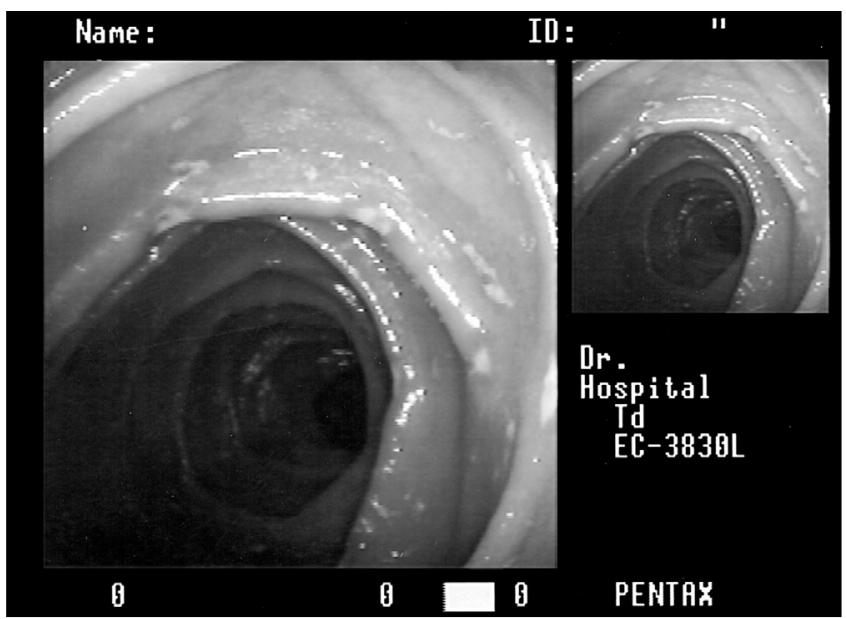

Figure 3) Colonoscopic demonstration of the virtual disappearance of ileal ulcers, June 1999

the dose of thalidomide was reduced to $50 \mathrm{mg} /$ day. Repeat colonoscopy revealed marked improvement of the ileal ulceration (Figure 2).

In June 1999 he came in for another colonoscopy. There was marked improvement of the appearance of the terminal ileum, with only a few small ulcers remaining (Figure 3 ).

It was decided at that time to continue the thalidomide for another three months and this was carried out. In late 1999 he felt well with no further symptoms and returned to work for the first time in three years.

A telephone conversation with his family practitioner in Cranbrook, British Columbia confirmed that up until January of 2003 the patient had been asymptomatic, off all medications, had gained $20 \mathrm{~kg}$ in weight and had returned to work. His hemoglobin remained stable.

\section{Summary}

A patient with intractable Crohn's ulcers in the terminal ileum achieved a complete remission after a short course of thalidomide. At the present time, he is asymptomatic and is not using any medication.

Thalidomide was supplied by the Celgene Corporation on a compassionate basis (Celgene Corporation, Attention Kathe Balinski, 7 Powder Horn Drive, Warren, New Jersey 07059, USA, telephone 732-271-1001, fax 732-271-4184).

\section{DISCUSSION}

Since the original publication by Wettstein and Meagher (3), there have been two large open-label studies of this drug in chronically active steroid-dependent Crohn's disease patients. Vasiliauskis et al (1) reported excellent results with low dose thalidomide $(50 \mathrm{mg} /$ day to $100 \mathrm{mg} /$ day). Ehrenpreis et al (2) also published an open-label trial on refractory Crohn's disease and during the trial the results were considered to be excellent. These were both open-label trials, and I have no knowledge of a double-blind placebo controlled trial with this drug as yet.

Since these reports, numerous other case reports and reviews on thalidomide have been the subject of numerous articles in the literature. Bousvarous and Mueller (4) reviewed 
the use of thalidomide in gastrointestinal disorders. Odeka and Miller (5) published a discussion of the use of thalidomide in oral Crohn's disease that was refractory to conventional medical treatment. All of these authors state that thalidomide in doses of $50 \mathrm{mg} /$ day to $300 \mathrm{mg} /$ day may decrease the severity of mucosal disease and prompt closure of fistulae. All authors state that patients who are placed on thalidomide therapy must practise either abstinence or strict birth control (Appendix I).

Women also must undergo regular pregnancy testing and use at least two forms of contraception. Bariol et al (6) reported on the early studies on the safety and efficacy of thalidomide for symptomatic inflammatory bowel disease. They felt that their data suggested that thalidomide was an effective short term treatment for refractory inflammatory bowel disease. I could find no reports that men should not have sexual relations when taking thalidomide and none of the reports I reviewed made mention of it.

Ginsberg et al (7) reported on the successful resolution of severe esophageal Crohn's disease with thalidomide in 2001. Facchini et al (8) reported from Italy on the use of long term thalidomide treatment in children and young adults with Crohn's disease. They felt that it was a safe and effective treatment in refractory Crohn's disease. That was the first report of long term use of thalidomide in refractory Crohn's disease in pediatric patients.

Ginsberg et al (9) reviewed the treatment of Crohn's disease with thalidomide and provided a detailed summary of the literature and the use of thalidomide for Crohn's disease. They stated, "Although it is usually tolerable, careful monitoring is recommended to prevent toxicity such as birth defects and peripheral neuropathy". They also stated that the drug appeared to work within four weeks, and had steroidsparing properties. It was also said to be particularly useful in treating oral and fistulous complications of Crohn's disease. They pointed out that thalidomide was known to inhibit angiogenesis as well as other well-described immunomodulatory properties. Bauditz et al (10) recently reported that thalidomide reduced TNF alpha, and interleukin-12 production in patients with chronic active Crohn's disease - "the clinical effects of Thalidomide thus far reported may be mediated by reduction of both TNF alpha and IL-12".

Other reports of the efficacy of thalidomide in Crohn's disease include its use in one case in vulvar ulcerations associated with Crohn's disease (11). Hegarty et al (12) reported its value in oral facial complications. Kane et al (13) reported the use of thalidomide as "salvage" therapy after infliximab delayed hypersensitivity. Sabate et al (14) reported its value for maintenance therapy in infliximab responses in patients with Crohn's fistulae. Ginsberg et al (9) recently summarized the current use of thalidomide in refractory Crohn's disease and discussed the recent development of thalidomide analogues.

\section{CONCLUSION}

To summarize, there has been recent literature suggesting that thalidomide may be valuable in the treatment of intractable Crohn's disease. This case report reveals one patient who has had an excellent recovery; he has not taken the medication now for three years and his recovery continues.

Thalidomide may be a reasonable alternative in steroidresistant Crohn's disease, but one has to be aware of the fact that it is a drug that will cause fetal abnormalities and should not be used in patients who are planning to become pregnant. Appropriate birth control methods should be used if it is decided to use this medication. It also has been reported that thalidomide can cause peripheral neuropathy, fatigue and headache (9) and one report of intractable insomnia (15). In our patient, headache and diplopia (previously unreported) were problems before the dosage of the drug was reduced from 100 $\mathrm{mg} /$ day to $50 \mathrm{mg} /$ day.

\section{APPENDIX I \\ Celgene corporation - general guidelines for taking thalidomide}

If you are female:

- You must discuss with your doctor the birth control methods that are best for you. If you are able to have children, you MUST use TWO methods of birth control. If you are not able to use hormonal birth control (birth control pills, implants, or injections) for medical reasons, it may be possible for you to use two barrier methods (condoms, diaphragms, cervical caps, vaginal pouches or contraceptive sponges).

- You must use TWO methods of birth control beginning at least four weeks before taking thalidomide, continuously while you take the drug, and for four weeks after you stop taking the drug.

- You must have a blood test done by your doctor which shows that you are not pregnant before you begin taking thalidomide.

- Remember that no method of birth control except completely avoiding sexual activity is completely reliable.

If you are male:

- You must read, understand and sign a consent form before you take thalidomide.

- You must not take thalidomide if you cannot avoid unprotected sex with a woman.

- You must use a condom EVERY TIME you have sexual intercourse with a woman while you are taking thalidomide, and for four weeks after you stop taking the drug.

- Remember that no method of birth control except completely avoiding sexual activity is completely reliable.

- You must inform your doctor IMMEDIATELY if:

- You have had unprotected sex with a woman.

- You think - FOR ANY REASON - that your female sexual partner may be pregnant.

- Your female sexual partner is pregnant.

\section{REFERENCES}

1. Vasiliauskis EA, Kam LY, Abreu-Martin MY, et al. An open label pilot study of low dose thalidomide in chronically active, steroiddependent Crohn's disease. Gastroenterology 1999;117:1278-87.

2. Ehrenpreis ED, Kane SV, Cohen LB, Cohen RD, Hanauer SG. Thalidomide therapy for patients with refractory Crohn's disease. An open label trial. Gastroenterology 1999;117:1271-7.

3. Wettstein AR, Meagher AP. Thalidomide in Crohn's disease. Lancet 1997;350:1445-6.

4. Bousvarous A, Mueller B. Thalidomide in gastrointestinal disorders. Drugs 2001;61:777-87.

5. Odeka EB, Miller V. Thalidomide in oral Crohn's disease refractory to conventional medical treatment. J Pediatr Gastroenterol Nutr 1997;25:250-1. 
6. Bariol C, Meagher AP, Vicars CR, et al. Early studies on the safety and efficacy of thalidomide for symptomatic inflammatory bowel disease. J Gastroenterol Hepatol 2002;17:135-9.

7. Ginsberg PM, Hanan I, Ehrenpreis ED. Treatment of severe esophageal Crohn's disease with thalidomide. Am J Gastroenterol 2001;96:1305-6.

8. Facchini S, Candusso M, Martelossi S, et al. Efficacy of long-term treatment with thalidomide in children and young adults with Crohn's disease: Preliminary results. J Pediatr Gastroenterol Nutr 2001;32:178-81

9. Ginsberg PM, Dassopoulos T, Ehrenpreis ED. Thalidomide treatment for refractory Crohn's disease: A review of the history, pharmacological mechanisms and clinical literature. Ann Med 2001;33:516-25

10. Bauditz J, Wedel S, Lochs $\mathrm{H}$. Thalidomide reduces tumor necrosis factor alpha and interleukin-12 production in patients with chronic active Crohn's disease. Gut 2002;50:196-200.
11. Kolivras A, De Maubeuge J, Andre J, Song M. Thalidomide in refractory vulvar ulcerations associated with Crohn's disease. Dermatology 2003;206:381-3.

12. Hegarty A, Hodgson T, Porter S. Thalidomide for the treatment of recalcitrant oral Crohn's disease and orofacial granulomatosis. Oral Surg Oral Med Oral Pathol Oral Radiol Endod 2003;95:576-85. PMID 12738949

13. Kane S, Stone LJ, Ehrenpreise ED. Thalidomide as "salvage" therapy for patients with delayed hypersensitivity response to infliximab: A case series. J Clin Gastroenterol 2002;35:149-50.

14. Sabate JM, Villarejo J, Lemann M, Allez M, Modigliani R. An open label study of thalidomide for maintenance therapy in responders to infliximab in chronically active and fistulizing refractory Crohn's disease. Aliment Pharmacol Ther 2002;16:1117-24.

15. Fox MR, Harris A. Intractable insomnia after cessation of treatment of thalidomide. Gastroenterology 2001;120:1567-8. 


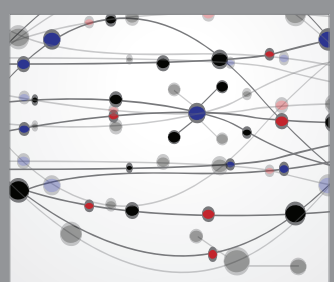

The Scientific World Journal
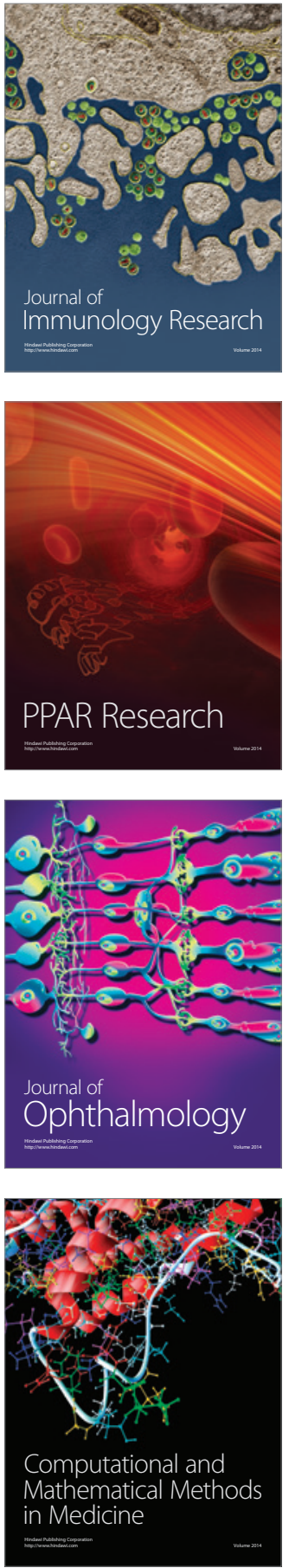

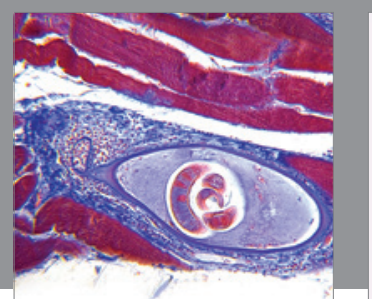

Gastroenterology Research and Practice

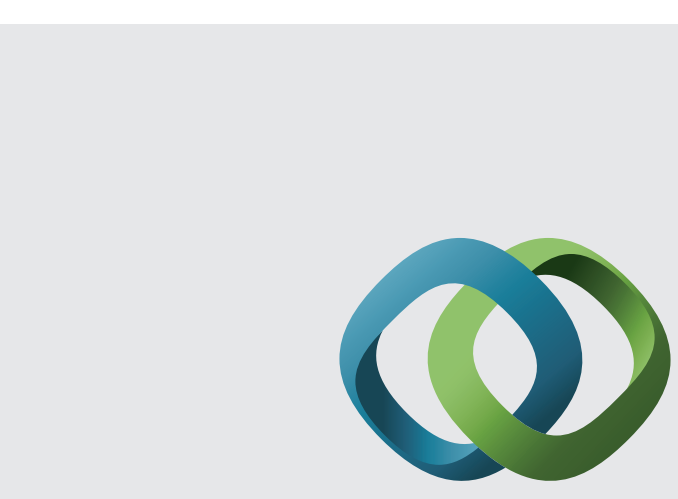

\section{Hindawi}

Submit your manuscripts at

http://www.hindawi.com
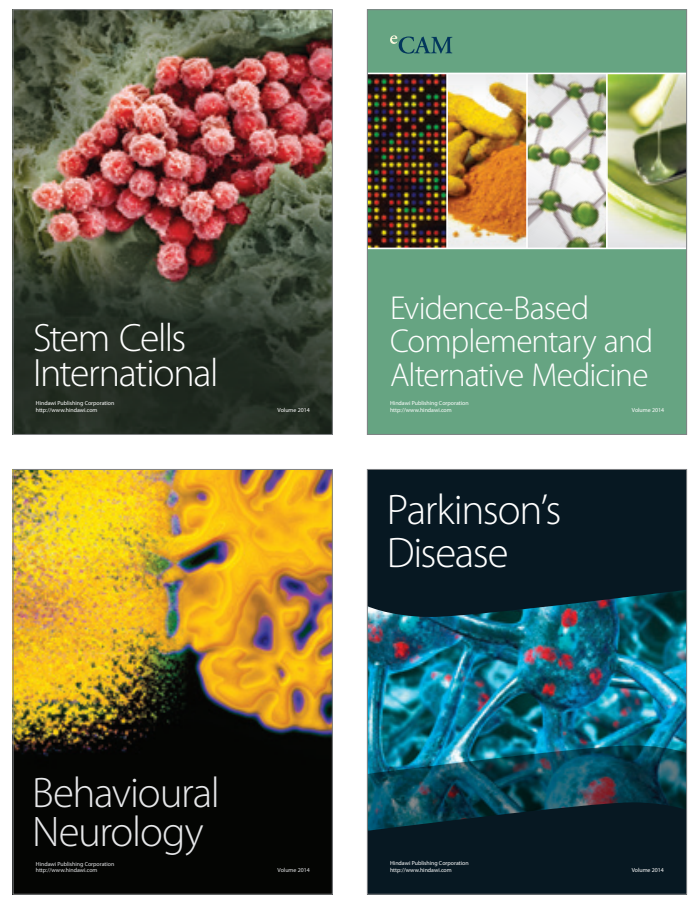
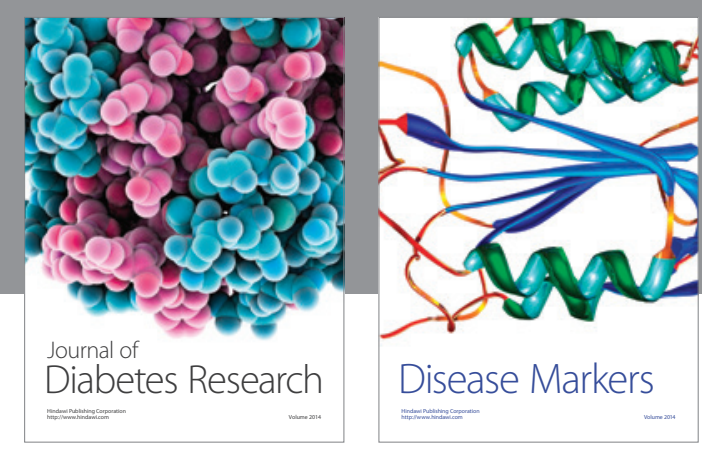

Disease Markers
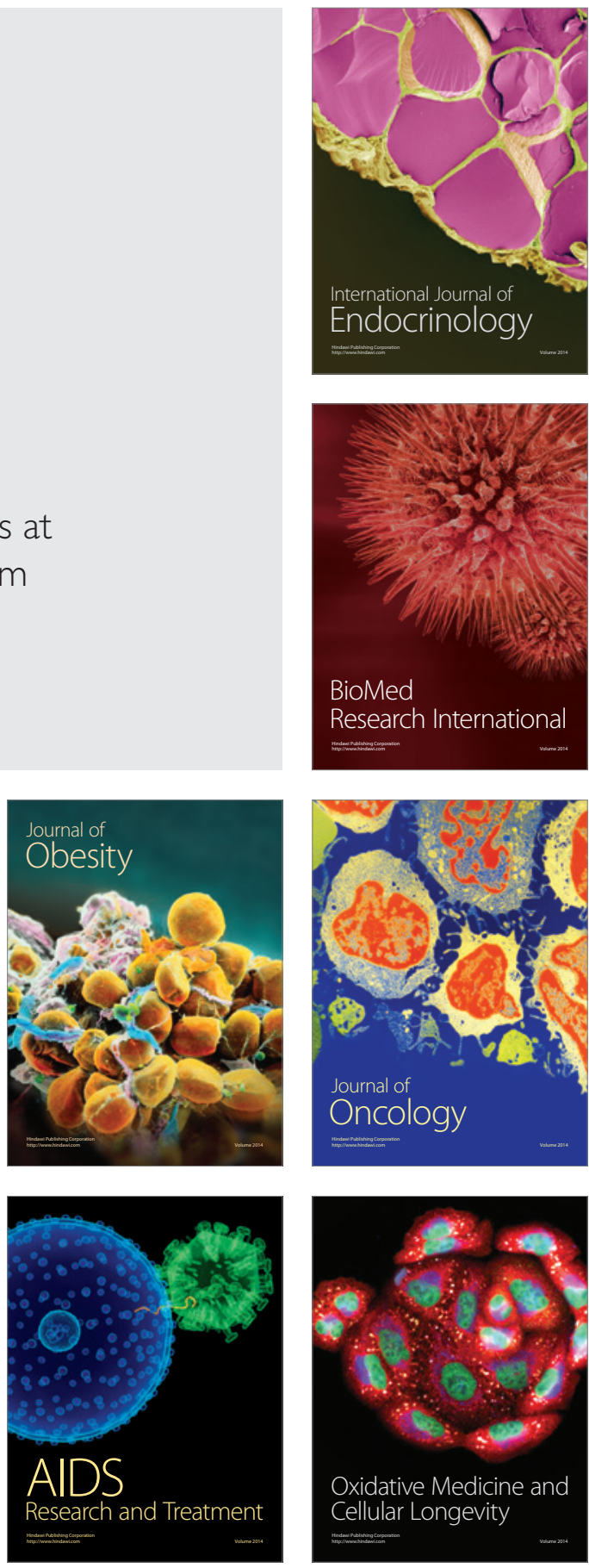